\title{
MODERNO E DÓS-MODERNO em diálogo na literatura portuguesa
}

Maria Theresa $\Lambda$ belha Nlves

Arte vem do latim ars, artis. É uma raiz na língua latina. É natural que venha também do grego. A etimologia desconhece-lhe a procedência. Temos, pois, que seguir por outros caminhos. Vamos, por exemplo às palavras compostas com a raiz latina Arte. E temos imediatamente artelho, articular, artificial, isto é, palavras que designam não só o movimento como também o próprio fornecimento do movimento. Além disto, encontramos também a palavra inerte que quer dizer 'sem movimento' ou à letra: sem arte. E a seguir aparece-nos o mais extraordinário destes exemplares, a palavra artilharia. [...] E neste caso o que significava então artilharia? Exatamente isso: o poder do engenho, a força do artifício. (Negreiros, 1997, p. 787)

Jacinto do Prado Coelho inicia o verbete "Modernismo", elaborado para o Dicionário de Literatura, ressaltando a novidade da concepção e teorização artísticas empreendidas pela geração de Orpheu, nomeadamente Fernando Pessoa, Mário de SáCarneiro e Almada-Negreiros, artistas que perseguiram uma poética intersemiótica, isto é, poética "em que a literatura surge associada às artes plásticas e por elas influenciada" (Coelho,1969, p.654), em consonância com as novas tendências européias, porém sem perder o vínculo com a raiz nacional.

Se no Modernismo a literatura se conjugou com as artes plásticas, nada melhor para defini-lo que as palavras que me servem de epígrafe, proferidas por Almada Negreiros, em 1933, em sua famosa conferência “Arte e artistas". Para Almada, poeta e pintor da aventura modernista portuguesa, a arte só se compreende como movimento, isto é, como câmbio simbólico, como interminável e não linear jogo semântico. É em torno desta arte que se quer metamorfose do real, jogo de sentidos (significados e/ou sensações) que, por volta de 1913, em Lisboa, constituíra-se o núcleo do grupo modernista português. Sá-Carneiro escrevera nesse ano o poema "Dispersão" que foi elogiado por Fernando Pessoa. Nesse mesmo ano, Almada-Negreiros expusera suas caricaturas, merecendo crítica de Fernando Pessoa nas páginas de A Águia. 
Formado estava o triunvirato estético do Modernismo português, pouco tempo depois desfalcado pelo suicídio de Mário de Sá-Carneiro, em1916, que suscitou a Fernando Pessoa o pensamento clássico "Morre jovem o que os Deuses amam" (PESSOA, 1974,p.455). Essa singular geração elaborou manifestos modernistas que, não inocentemente, foram chamados de "ultimatum", talvez porque, como bem observou Teresa Cristina Cerdeira, estava vivendo "num Portugal que ainda sente o duro peso de um outro - 27 anos antes - que o acusava justamente de falência e de descompasso com o progresso europeu" (Cerdeira, 2000, p.125). Vivendo uma época de crise, pois a Europa passava pela experiência da Primeira Guerra Mundial, "jogo de empurra do lado de cá e jogo de porta do lado de lá!” (Campos, 1974, p. 511 ), os jovens de Orphen só poderiam adotar uma conduta bélica contra os valores degradados que a sociedade européia, sobretudo a portuguesa, ainda teimava em celebrar como seus, só poderiam lavrar , como o fez o heterônimo Álvaro de Campos, o "mandado de despejo aos mandarins da Europa!" (p. 508), entre os quais se incluíam os representantes da arte, da filosofia e da ciência política ultrapassadas, responsáveis, segundo o manifestante, pela "Falência geral de tudo por causa de todos! Falência geral de todos por causa de tudo! Falência dos povos e dos destinos - falência total!" (p. 510). Esse clima de ruína civilizacional, falência dos homens e de suas certezas, falência das nações e de seus projetos, obrigava as consciências a uma reação. O engenheiro naval Álvaro de Campos, máscara pessoana presa a seu tempo, soube bem traduzir tal clima e a necessidade de contra ele reagir. De reagir, principalmente, ao "Portugal-centavos, resto de Monarquia a apodrecer República, extrema-unção-enxovalhado da Desgraça, colaboração artificial na guerra com vergonhas naturais em África!" (p. 510). Por isso, em tom confessional, grita em seu "Ultimatum":

\section{Sufoco de ter só isto à minha volta! \\ Deixem-me respirar! \\ Abram todas as janelas! \\ Abram mais janelas do que todas as janelas que há no mundo. (p. 511)}

Esse ato rebelde de abrir janelas para a salutar renovação do ar haveria de abolir os dogmas e preconceitos consagrados pela tradição: o dogma da personalidade, o preconceito da invidualidade e o dogma do objetivismo pessoal. A demolição desses dogmas haveria de trazer conseqüências profundas para a arte. À queda do primeiro deles corresponderia a "abolição total do conceito de que cada indivíduo tem o direi- 
to ou o dever de exprimir o que sente" (p. 517). À queda do segundo, corresponderia a "abolição do dogma da individualidade artística" (p. 518). Finalmente, à queda do terceiro, corresponderia a "abolição do conceito de Expressão, substituído por o de Entre-Expressão” (p. 519). O engenheiro naval modernista proclamava o seu "Ultimatum" de olhos fitos no Atlântico e no Infinito, ciente de que o método capaz de revolucionar a arte, a política e a filosofia pertence a toda uma geração: "O Método sabe-o só a geração por quem grito, por quem o cio da Europa se roça contra as paredes!" (p. 520). Ao poeta competia a visão do "Caminho", visão, portanto, da arte que não é inerte, que é atividade de artelho, que é via de mudança.

Esse ato rebelde de abrir as janelas ao novo alimenta também o "Ultimatum Futurista" de Almada-Negreiros. Em 1917, o poeta-pintor de Orpheu brada contra a literatura que se apóia no “atavismo alcoólico e sebastianista de beira-mar" (Negreiros, 1997, p. 653), e nas tradições pequeno-burguesas. Numa série de mandamentos contrários à razão burguesa, Almada-Negreiros conclama, furiosa e anarquicamente, os portugueses a uma metamorfose comportamental, ética e estética: "Insultai o perigo", "Desejai o record", "Divinizai o orgulbo", "Rezai a Luxúria", "Abandonai os políticos de todas as opiniões" (p. 664).

Álvaro de Campos ironizara a participação de Portugal na Primeira Grande Guerra, considerando-a "colaboração artificial”. De igual modo, Almada Negreiros declara sua profunda tristeza com o desempenho bélico português e demonstra sua desaprovação à "fúria de incompetência com que Portugal participa da Guerra Européia" (p. 646). Almada Negreiros, em seu Ultimatum, utiliza a palavra guerra com um duplo sentido (Cerdeira, 2000, p.126). Guerra é, denotativamente, o conflito bélico em que a Europa se encontra envolvida e no qual o papel de Portugal é secundário. Guerra é, conotativamente, a luta contra as "proporções do valor acadêmico, todas as convenções de arte e de sociedade", a luta que "desloca o cérebro do limite doméstico pra concepção do Mundo, portanto da Humanidade" (Negreiros, 1997, p. 651), guerra, enfim, que capacite os portugueses a criarem "a pátria portuguesa do século XX” (p. 654), a saírem da inércia, a adotarem a arte que é mudança, arte que se traduz tanto como movimento espacial, enquanto assunção de uma dimensão européia e universal, quanto como movimento temporal, projeção que é para o novo, para o futuro, arte que é artilharia.

É em meio a esse clima de guerra num e noutro sentido, é em meio aos ares de renovação artística que Portugal vivia com a geração de Orpheu, que acontece em Portugal, no Salão do Jardim Passos Manuel, no Porto, e na Liga Naval de Lisboa, em 1916, a "Exposição de Amadeo de Souza-Cardoso", pintor que participaria do terceiro número da revista Orpheu, como Fernando Pessoa anunciara em carta a CortesRodrigues, datada de 4 de setembro de 1916: 
Vai sair o Orpheu 3. É ai que, no fim do número, publico dois poemas ingleses meus, muito indecentes, e portanto, impublicáveis em Inglaterra. Outra colaboração do número:[...] A Cena do Ódio do Almada-Negreiros (que está atualmente homem de gênio em absoluto, uma das grandes sensibilidades da literatura moderna),[...] Orpheu 3 trará, também, quatro hors textes do mais célebre pintor avançado português - Amadeu de Souza Cardoso. (Pessoa, 1974, p. 416).

O terceiro número de Orphen deveria sair nos fins de setembro de 1916, mas, infelizmente , não veio a público naquele altura. O número já estava quase totalmente impresso quando Fernando Pessoa escreve a Cortes-Rodrigues. Para apresentá-lo, o autor de "Chuva Obliqua" redigira notas em inglês, considerando esse volume da revista como "a soma e a síntese de todos os movimentos literários modernos". É através desses três artistas que, entre outros, figurariam no Orphen 3 - Pessoa, Almada e Amadeu - que proponho o diálogo do Modernismo e do Pós-Modernismo português.

Em 1984 foram publicados, em Portugal, dois romances da mais alta qualidade literária. Ambos foram indicados para o prêmio de melhor romance do ano pela Associação Portuguesa de Escritores. Um deles obteve o prêmio, mas ambos obtiveram a consagração. As obras em questão são Amadeo, de Mário Cláudio e $O$ ano da morte de Ricardo Reis, de José Saramago. O primeiro recebeu o prêmio na altura de sua publicação, o segundo, juntamente com toda a anterior e posterior obra de seu autor, valeu a Saramago o reconhecimento mundial e a glória de ser o primeiro Nobel de literatura em língua portuguesa. Porém não são os prêmios que me fazem convocar os dois autores e os dois romances para trazê-los aqui. São as personagens que tais romances (bio)grafam: Ricardo Reis, uma das máscaras pessoanas e Amadeo de Souza-Cardoso. Este em diálogo latente com Almada Negreiros, o outro grande pintor do movimento modernista, o autor do "Ultimatum Futurista"; aquele com o diálogo manifesto com Fernando Pessoa e os outros heterônimos, principalmente Álvaro de Campos, o autor do outro "Ultimatum" da modernidade. Passados quase setenta anos da publicação do primeiro número de Orpheu, os autores portugueses pós-modernos encontram nas várias faces de Fernando Pessoa e nos pintores Amadeo de Souza-Cardoso e Almada Negreiros o meio eficaz para interpretarem o tempo e o país que esses modernistas, em suas obras, tão bem souberam traduzir.

Comecemos por Amadeo. Àquela exposição que Souza-Cardoso fizera, em 1916, no Jardim Passos Manuel, iria, segundo Mário Cláudio, um "cavalheiro" inerte em seus hábitos e valores, acostumado à "cabeça-de-pescada de todos os anos" (Cláudio, 1984, 95), à máscara social do "ameno semblante[...] para a despedida dos amigos e a gorjeta do porteiro” (p. 96) do clube que com assiduidade freqüentava. Esse cidadão, 
porque preso à comodidade do antigo, é incapaz de compreender o novo; porque inerte, não é capaz de compreender a metamorfose operada pela obra de Souza-Cardoso e, diante dos cento e catorze quadros expostos sente-se insultado e,

Aproximando-se de Amadeo, que folheia o jornal, encara-o com ódio, escarra com fragor sobre uma tela. Não replica o artista, obrigando os músculos à contenção, retorna às páginas do jornal. Ele sabe como lhe convém, para que possa persistir na caminhada, a palma verde do martírio. (Cláudio, 1984, p. 96).

À exposição que Souza-Cardoso fizera na Liga Naval de Lisboa, um mês após a do Jardim Passos Manuel, Almada Negreiros iria como crítico de arte e como pintor. Ao contrário do conservador cidadão portuense, o futurista de Lisboa ${ }^{1}$ sabia que na etimologia de arte estava o sentido de mudança, de caminhada (a arte é raiz de artelho) em direção ao novo e ao futuro. Ao contrário dos críticos que se confrontaram com o novo sem o endender, "que são os jornalistas com uma coluna onde expendem a crítica da música e do teatro, da pintura e do circo, [e que] acolhem o efervescente "pintor Cardoso" com uma preleção magnífica de flibusteiro galante" (p. 97), Almada Negreiros a ele confere o juízo merecido. Para Almada, a exposição de Amadeo é a "Primeira descoberta de Portugal na Europa do século XX" (Negreiros, 1997, p. 646). O poeta-pintor de Orpheu viu na exposição de Amadeo o comparecimento português à modernidade européia, porque na obra do manhufense "o limite da descoberta é infinito porque o sentido da Descoberta muda de substância e cresce em interesse"(p. 647). Almada, naquele momento, não analisara a obra de Amadeo, permanecera deslumbrado perante a explosão de novidade que ela trazia à cena artística portuguesa, mas convocava seu leitor a ir à exposição, pedindo-lhe que tapasse os ouvidos às críticas negativas que a ela foram feitas, incitando-o a deixar os olhos correrem sobre as telas e advertindo-o: "Não esperes porém que os quadros venham ter contigo, não! Eles têm um prego atrás a prendê-los. Tu é que irás ter com eles"(p. 647). A arte que não é inerte suscita caminhadas. A arte de Amadeo concretizava, para Almada, a atitude do fruidor perante a arte moderna: abandono da inércia e opção pela metamorfose comportamental: os olhos devem correr sobre essa arte que exige a disponibilidade para a leitura intranqüila, leitura desconfortante que contradiz valores e lembranças, leitura que ousa modificar os padrões de gosto, leitura que se aventura a ir ao encontro do prego que sustém a arte.

$1 \mathrm{O}$ Modernismo português foi um fenômeno tipicamente lisboeta. Almada Negreiros, apesar de não ser lisboeta em termos de origem, pois nascera nos Açores, sem dúvida o era em termos de pensamento. 
Amadeo teria privado, com algum mal-estar, da companhia de Almada Negreiros nas raras vezes que deixava o Norte por Lisboa. Mário Cláudio surpreende esse desconforto, nascido de mútua fascinação e de mútua repulsa. Os dois grandes artistas eram irmãos na arte, mas muito diferentes em atitudes: o nortenho, austero e meticuloso, o lisboeta, clownesco, este de palavras muitas, aquele de palavras poupadas:

Nas espaçadas idas a Lisboa, igualmente se barricará da ininterrupta alucinação que é o trato com José de Almada Negreiros. Equilibrado na borda dos passeios, com outra concepção do afã especulativo que se caldeia na tontura da prestidigitação inesgotável, veria Almada o rapazote duriense com alguma mistura de displicência e consideraşão. Anunciará aquele, por essa época, uma excursão mitológica à coterie de Vila do Conde, com a latente ameaça de entrar de roldão portas adentro, secundado por um perdigueiro e duas cegonhas cubistas, um macaco e outros bicharocos. Fosse Amadeo menos esforçado na oposição de seus músculos ao vigor com que medravam os tojos na vertente por detrás da Casa de Manhufe, e eis que um fulano assim apenas poderia aterrá-lo. Com seu subitâneo impulso para esquissar uma coreografia, que logo exemplificava em plena Rua Garrett, não conseguia Almada envinagrar a temperança do pintor lá de cima. Contrapunha-lhe este a exatidão da finalidade e a boa maneira do silêncio, defrontando-o a partir da imagem que de si mesmo dava, de perene e incansável desbravador do recanto que the coubera em sorte. (Cláudio, 1984, p. 101-102).

Mário Cláudio faz, em Amadeo, outras alusões que remetem ao encontro dos dois artistas , cita, por exemplo, o próprio Almada que atribui a seu "K4 O Quadrado Azul" um destinatário: "Amadeo de Souza-Cardoso, substantivo ímpar 1, o detentor da Apologia Masculina, o que me possui em tatuagem azul na sensibilidade, o Amante preferido da Luxúria e do Vício" (Negreiros, 1997, p. 361). O fascínio exercido por Souza-Cardoso em Almada decorrera da sintonia entre as concepções artísticas de ambos. Almada via a arte como movimento, no movimento para ele se instaurava o novo. Amadeo assim também concebia a arte. Lembremos que um de seus guaches se denomina "Expositions Mouvantes. Corporation Nouvelle". Mário Cláudio também vê no movimento o cerne da pintura de Souza-Cardoso, pois no centro dela coloca a imagem do "viravento multicor da infância" (p. 91), precisamente o mesmo que se multiplica no guache acima citado.

Como Sá-Carneiro, Amadeo também morrera precocemente. Fora vítima da mazela que se segue a toda guerra, fora vítima da "febre espanhola", que o levara em três dias. Como se expõe em Amadeo, "Nesse vinte e sete de Outubro de mil novecentos e dezoito, a vida que findara começava, como todas as que se extinguem, no reaver do palpitar definitivo de suas cores" (p. 112). Morto o artista, vivas permanecem as tintas com que soube pintar seu tempo, vivas permanecem as cores com que soube ler, com grandes, absolutos e definitivos olhos, o espetáculo do mundo, a ponto de sobre ele ser possível dizer o que Fernando Pessoa dissera de Sá-Carneiro: "Morre jovem o que os Deuses amam". 
Quase quarenta anos transcorridos da morte de Souza-Cardoso, na primavera de 1959 , dá-se a "Exposição Retrospectiva de Amadeo". O mesmo Almada que tanto admirara o pintor amarantino volta a se referir a ele e o faz em nome da geração modernista, dizendo: "Em Portugal, no nosso século, dois gritos de Poesia se ouviram: Mário de Sá-Carneiro e Amadeo de Souza-Cardoso. Poesia das letras e Poesia das cores"(Negreiros, 1997, p. 1075). Retoma o epíteto com que consagrara o pintor aquando de sua primeira exposição em Lisboa. Passados tantos anos, Almada ainda considerava a abra de Amadeo "a primeira descoberta de Portugal no século XX". No Catálogo da Exposição de 1959, Almada já não se furta a analisar a obra de Amadeo, e relembra a primeira vez que fora à terra natal do pintor e que pudera encontrar na luz da paisagem as mesmas cores e as mesmas proporções com que o amarantino pintara seus quadros, tanto os da primeira fase, influenciados pela vida burguesa do Porto, quanto os da segunda fase, influenciados pelo universalismo de Paris. Constatando a portugalidade dos quadros, Almada declara:

Toda a sua arte reflecte o seu rincão natal. E nunca é o rincão natal o que o pintor retrata. $O$ seu rincão natal são as suas próprias cores, as do seu rincão natal. Foram estas as cores que teve para comesar a sua mensagem de poeta. Entre começá-la e conclui-la já sabem o que aconteceu. (p. 1076).

O que aconteceu foi a arte verdadeira. Amadeo de Souza-Cardoso soube manter em cores um diálogo fecundo com a natureza, diálogo que não se efetivou através da mera cópia, mas que se fez por metamorfose, pelo artifício, pela recusa à inércia da pura mímese e que, por isso mesmo, pôde fielmente traduzir o seu país. O postulado sobre que repousa a opinião de Almada serve tanto para a arte moderna de Amadeo de Souza-Cardoso quanto para outra qualquer absoluta arte, porém a modernidade tem exarcebado a consciência de que o mundo da arte é o do artifício, de modo que a única coincidência verdadeiramente possível entre arte e natureza é a oposição, por isso, toda a arte de Amadeo refletiu " o seu rincão natal", sem contudo o fotografar.

Setenta anos passados sobre a aventura de Orpheu, surge, para falar do artista do pincel um outro colorista que com palavras sabe pintar, Mário Cláudio, escritor que tecera seu romance Amadeo a partir de uma visão da arte que Almada intuíra estar na pintura de Souza-Cardoso. Amadeo pintara Portugal sem fazer retrato de Portugal, Mário Cláudio, percorrendo os quadros do pintor como Almada um dia percorrera, retoma plasticamente as obras do pintor e nelas e através delas faz surgir Portugal, enquanto paisagem física e humana, faz surgir o tempo de Orphen e o mundo artístico que tal revista evoca. Tal como o biografado, o biógrafo compartilha da mesma visão sobre a arte. Mário Cláudio, em seu romance pós-moderno, Amadeo, tal como fizeram 
os artistas de Orpheu, em especial como fizera o pintor manhufense, aprofunda o estilhaçar do espelho realista em prol de uma arte que, recusando a cópia do real o pudesse recuperar em outra instância. Assim faz o leitor caminhar das páginas escritas que descrevem os quadros de Amadeo, às reproduções dos mesmos inseridas no romance e destas às fotografias das pessoas e paisagens que os quadros traduziam, é o que ocorre com a "Casa de Manhufe", com a "Cozinha da Casa de Manhufe", com o "Auto-retrato de Amadeo", com o "Retrato de Lúcia". O artista pós-moderno, recuperando o tempo e o espaço do Modernismo português, oferece a seus leitores uma "literatura[que] surge associada às artes plásticas e [que é] por elas influenciada", portanto literatura que retoma a concepção artística do Modernismo ${ }^{2}$. Revitalizando as características modernistas, ao fornecer a transcrição das obras de Amadeo, cria um segundo quadro por plásticas palavras, e o leitor, percorrendo as fotografias, os quadros de Amadeo e os quadros fixados pela escrita, experimenta a distância que existe entre o real e a arte, e experimenta o quanto nessa distância a arte pode ser verdadeira. Assim faz o leitor acompanhar a evolução da biografia de Amadeo como uma vera ficção, isto é, não a vida, mas a arte: "Estamos a milénios da vera crónica de Amadeo de Souza-Cardoso, recriamos o que nunca foi ou para sempre se esconde" (Cláudio, 1984, p. 53).

Passemos para $O$ ano da morte de Ricardo Reis. Não estamos mais em tempos de Orpheu. Fernando Pessoa morrera já, vivas estavam suas ficções: seus heterônimos e seus versos. O tempo é o conturbado ano de 1936, tempo da Guerra Civil Espanhola, vésperas da Segunda Guerra Mundial, tempo de ditadura em Portugal. José Saramago, a partir de poemas de Fernando Pessoa (o poeta ele-mesmo e seus heterônimos) constrói o que Maria Alzira Seixo denominou "uma ficção do texto"(Seixo, 1983, p.21), encenando um tempo, o ano de 36, a partir da metáfora do labirinto e do jogo, imagens cinéticas da modernidade.

O romance apresenta dois jogos (amarelinha e xadrez) que espelham o jogo inter, intra e transtextual. A imagem labiríntica que condiciona tais jogos promove o resgate do espaço fechado e opressivo da cidade de Lisboa, em 36, que aprisiona o protagonista, Ricardo Reis, condicionando-o a sempre se voltar sobre seus próprios passos e andar constantemente nos mesmos sítios. Através dessa deambulação circu-

2 Convém lembrar que uma das principais características do pós-modernismo é precisamente o exercício da citação. Em Amadeo há citações de falas de outros artistas (Almada Negreiros, Manuel Laranjeiras, Robert e Sonia Delaunai) de cartas de Amadeo a seus familiares, de críticas jornalísticas às obras de Amadeo, de passagens dos livros que Amadeo por ventura estivesse lendo (Proust e Rimbaut) e, principalmente, há a retomada de procedimentos modernistas, isto é, citação do estilo e da mentalidade de uma época. 
lar, o heterônimo contempla o espetáculo do mundo, obedecendo à máscara que Fernando Pessoa lhe dera. Assim se vê diante dos mitos com que a nação portuguesa teima em, nostalgicamente, se reconhecer, aqueles mesmos mitos que a geração de Orphen execrara nos seus "Ultimatos", aqueles mitos voltados para o passado, aqueles mitos saudosistas que se sustentam das imagens petrificadas da glória náutica portuguesa, imagens de "atavismo alcoólico e sebastianista de beira-mar", no lúcido dizer do modernista Almada-Negreiros. Assim Ricardo Reis saramaguiano sempre passa diante da estátua de Camões e da estátua do Gigante Adamastor. Assim também Ricardo Reis recebe, em sua retina contemplativa, as imagens conturbadas do tempo, imagens que lhe provam que, afinal, não são plácidas todas as horas.

Há o labirinto do livro de Herbert Quain que Ricardo Reis está a ler, sem nunca conseguir terminar, livro de um autor cujo sobrenome, fonologicamente, instaura a pergunta: - “Quem?”, pergunta que abre o jogo da heteronímia, jogo da aventura existencial e ontológica tão sabiamente realizada por Fernando Pessoa nos meandros da ficcionalização do eu. Esse é o labirinto que resgata o livro Ficções, de Jorge Luís Borges, e que aponta para a pluralidade de ficções na ficção, que aponta para a ficção feita de fricções, isto é, de citações de alheias linguagens. Ricardo Reis sempre volta a Herbert Quain e às primeiras páginas do livro - The God of the Labyrinth - que o suposto autor teria escrito. Para acentuar o abandono do espelho realista (abandono que os modernistas impunham em seus Ultimatos e que a pós-modernidade exacerba), Saramago cria o interessante jogo de fazer uma ficção de Fernando Pessoa Ricardo Reis - folhear outra, escrita por Herbert Quain, ficção de Borges.

O fio da heteronímia pessoana é o maior e o mais enovelado no labirinto textual do romancista contemporâneo. Isso porque Pessoa soube, como ninguém, que o espaço da identidade é transacional, por isso a "companhia" da heteronímia e do Pessoa ele-mesmo é fundamental para a compreensão desse Ricardo Reis. Não só aquela heteronímia fixada pelos versos de cada uma das personalidades em que Pessoa se constelou, mas a heteronímia buscada em seus grandes temas, em suas cenas. É interessante o xeque-mate que Saramago prega a seu leitor: Pessoa, no romance, é um fantasma que aparece para Ricardo Reis e que com ele dialoga; no entanto, a figura que fantasmaticamente preenche o romance é a do heterônimo Álvaro de Campos. Esta é a grande sombra projetada sobre Ricardo Reis.

Construído sobre o hipotexto de Pessoa, o hipertexto saramaguiano é um outro que corresponde, simultaneamente, a uma derivação e a uma transformação. Nessa dimensão transtextual, circulam cenas e falas do engenheiro Álvaro de Campos, na composição do olímpico médico Ricardo Reis. Este revisita Lisboa, sentindo-se "es- 
trangeiro" na cidade "como em toda parte" (Campos, 1965, p. 360). Ricardo Reis surpreende Marcenda sentada no restaurante do hotel, no entanto não é como musa das Odes que ela é vista. É com os olhos de Álvaro de Campos, que o médico a vê: "Olho, desterrado de ti, as tuas mãos brancas/ Postas, com boas maneiras inglesas, sobre a toalha da mesa[...] Não tiro os olhos de tuas mãos" (p.387). O medo do ridículo, profunda vivência de Campos em "Poema em linha reta", é o sentimento que Reis experimenta ao se sentir velho para a jovem musa e ao se envergonhar da ligação que tem com Lídia, talvez supondo ser "cômico às criadas do hotel” (p. 419).

Como Álvaro de Campos, Ricardo Reis é suspeito de ser monarquista, vive a experiência do adiamento, percebe, com a sagesse do engenheiro naval, que os navios atracados no cais são outra coisa "E não apenas navios, indo e vindo" (p.317). No final do romance, a imagem de Ricardo Reis é a mesma de Álvaro de Campos em "Tabacaria", isto é, o protagonista está "vencido, como se soubesse a verdade", e "lúcido, como se estivesse para morrer" (p. 363).

O projeto Modernista da geração de Orpheu , divulgado em forma de "Ultimatum" por Álvaro de Campos, compreendia a abolição do dogma da personalidade, do preconceito da invidualidade e do dogma do objetivismo pessoal que a criação heteronímia pessoana levou ao extremo . A obra pós-moderna que adota como protagonista um personagem do "drama em gente" ousa tocar no consagrado universo poético pessoano, metamorfoseando-o. A leitura que o pós-modernismo faz do "dogma” da heteronímia não é uma leitura inerte, não é uma leitura passiva diante do universo das Odes, é leitura que caminha na certeza de que depois de tudo determinado pela clássica e olímpica atmosfera em que transitara Ricardo Reis, há o infinito por reescrever, pois a permanência da origem ou a singularidade irredutível são meros lugares vazios.

Por que entre os heterônimos de Fernando Pessoa, Saramago elegeu Ricardo Reis? Num de seus pronunciamentos sobre a literatura, o autor esclarecera: "só se inventa o que não existe ainda [...] inventa-se porque, conscientemente ou não, uma exigência imperiosa o reclama" (Saramago, 1989, p. 45) . A existência de Reis compreendia a passividade olímpica diante do mundo. Ler o mundo com a medida clássica já não é possível. Um personagem em desmedida reclamava por invenção. Um Reis que não se contentasse com o espetáculo do mundo mas que, pelo menos, estivesse conivente com os que buscavam construir o espetáculo do mundo. A transformação artística efetuada por Saramago passa pela revolução íntima que retira o heterônimo de sua torre olímpica e o planta no século XX. Álvaro de Campos é a pessoa de Pessoa verdadeiramente contemporânea dos grandes mitos e das maiores desgraças das primeiras décadas do século, é o heterônimo mais comprometido com as coorde- 
nadas vanguardistas do Modernismo, pois é aquele melhor qualificado pelo atributo de "homem de seu tempo". Jogando com a heteronímia, o romancista, para viabilizar a transformação de Ricardo Reis, faz sua personagem encenar a proposta elaborada por Caeiro, o grande mestre de todos (no poema 24 de Guardador de Rebanhos) e, assim, no ano de sua morte, Ricardo Reis vive a "aprendizagem de desaprender" (Pessoa, 1965, p. 217), nascendo outro, ator e não espectador.

Os dois romances aqui focalizados, colocando em cena figuras capitais do Modernismo Português, retomaram conceitos modernistas, relembraram a mentalidade da época e as circunstâncias históricas que motivaram a virada estética da geração de Orpheu, por isso permitem que neles se leia o Modernismo português. Os dois romances aqui focalizados, por outro lado, ao reviverem artistas, obras e tempo, empreendem, ludicamente, a simultânea inscrição e subversão de convenções da arte e da teoria. Amadeo conjuga o discurso memorialista, o discurso biográfico e auto-biográfico, o ensaio de artes plásticas e o discurso histórico. O ano da morte de Ricardo Reis conjuga o discurso histórico, o ensaio filosófico (não é inocente o narrador entre os fatos ocorridos em 1936 focalizar a edição portuguesa de O Desespero Humano, de Sören Kierkegaard), o ensaio literário, o biográfico. Ocupando vários "gêneros", os dois romances não se podem classificar por um único deles, parodisticamente, a citação de todos esses gêneros, ao esgarçar os limites genéricos, subverte as convenções sobre que eles se engendram. Citando, parodiando e subvertendo, os dois romances se oferecem à leitura como um desafio à cultura a partir do interior dela mesma. As questões como narrativa, referência, subjetividade, intertextualidade são objetos de reflexão, como é também o discurso combinado da história, da teoria e da ficção, por isso os dois romances podem ser inseridos na categoria denominada por Linda Hutcheon de "metaficção historiográfica", na categoria pós-moderna dos romances que encenam "o passatempo do tempo passado" (Hutcheon, 1991, p. 141), quando, lembrando o Modernismo, encenam o diálogo entre as grandes figuras da literatura e das artes plásticas deste movimento, quando ensinam ao leitor que a arte é jogo cinético multi-orientado que exercita os artelhos em direção à obra, para dentro dela, e para o exterior em que ela buscou sua verdade, quando convocam o leitor a abandonar a inércia, quando o convidam a sempre novas e sempre outras caminhadas.

\section{sox?}




\section{BIBLIOGRAFIA}

ALVES, Maria Theresa Abelha. "O ano da morte de Ricardo Reis: uma aventura pelo labirinto ". In: LIMITES. Anais do $3^{\circ}$ congresso ABRALIC. São Paulo: Edusp, 1995, v. 2, p. 397-404.

BERARDINELLI, Cleonice. Edição crítica de Poemas de Álvaro de Campos. Lisboa: Imprensa Nacional-Casa da Moeda, 1990.

CERDEIRA, Teresa Cristina. “Um pintor e dois olhares: Amadeo entre Almada e Mário Cláudio”. In: $O$ avesso do bordado: ensaios de literatura. Lisboa: Caminho, 2000.

CLÁUDIO, Mário. Amadeo. Lisboa: Imprensa Nacional-Casa da Moeda, 1985.

COELHO, Jacinto do Prado. “Orpheu”. In: Dicionário de Literatura. (v.2) Rio de Janeiro: Companhia Brasileira de Publicações, 1969, p. 773 -774

COELHO, Jacinto do Prado. "Modernismo". In: Dicionário de Literatura (v.1). Rio de Janeiro, Cia. Brasileira de Publicações, 1969, p. 654

HUTCHEON, Linda. Poética do pós-modernismo: história, teoria, ficção. Rio de Janeiro: Imago, 1991.

MARQUES, Maria Theresa Abelha Alves. "Amadeo: cor \& palavra em contágio". In: Boletim do SEPESP: v.3. Rio de Janeiro, UFRJ, s/d. p. 107-128.

NEGREIROS, Almada. "Ultimatum Futurista", "Arte e artistas", "Manifesto da Exposição de Amadeo de Souza-Cardoso", "Madeo de Souza-Cardoso" e "Vistas do SW”. In: Obra Completa (Org. Alexei Bueno). Rio de Janeiro, Nova Aguillar, 1997.

PESSOA, Fernando. Obra Poética. Rio de Janeiro: Aguilar, 1965.

PESSOA, Fernando. Obras em Prosa. Rio de Janeiro: Aguilar, 1974.

SARAMAGO, José. O ano da morte de Ricardo Reis. Lisboa: Editorial Caminho, 1984.

SARAMAGO, Jose. "Sobre a invenção do presente”. In: Jornal das Letras, artes e Ideias. Lisboa: 26 fev.-6 mar., 1989 , p. 45.

SEIXO, Maria Alzira. "Entre a Leitura-escrita e a Leitura-crítica: a fala do literário”. In: Jornal das Letras, Artes e Idéias. Lisboa: 8-21 nov., 1983, p. 21.

SEIXO, Maria Alzira. A palavra do romance. Lisboa: Livros Horizonte, 1986.

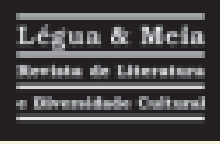

ALVES, Maria Thereza Abelha. Moderno e pós-moderno em diálogo na literatura portuguesa. Légua \& meia: Revista de literatura e diversidade cultural. Feira de Santana: UEFS, n¹, 2002, p. 162-173.

Maria Theresa Abelha Alves é Professora Titular da UEFS, onde exerce o cargo de Coordenadora da Pós-Graduação. Mestre e Doutora em Literatura Portuguesa pela UFRJ, onde fez carreira como docente, e Pós-Doutora em Literatura Portuguesa pela Universidade Nova de Lisboa. Publicou artigos, ensaios e livros, no Brasil e no Exterior. Entre seus principais trabalhos destaca o livro, publicado em Portugal, A Dialética da Camuflagem nas Obras do Diabinho da Mão Furada. 